\title{
The Role and Stance of Francis Bacon in Initiating Environmental Crisis Occurrences
}

\author{
Mohammad Bidhendi ${ }^{1}$, Rezida Nigomatullina ${ }^{2} \&$ Mohsen Shiravand ${ }^{2}$ \\ ${ }^{1}$ Department of Philosophy, University of Isfahan, Iran \\ ${ }^{2}$ Department of philosophy, Kazan (Volga) Federal University, Russia \\ Correspondence: Mohsen Shiravand, Universiade Village, Parina, Kazan, 420010, Russia. E-mail: \\ m.shiravand23@gmail.com
}

Received: September 22, 2014 Accepted: October 13, $2014 \quad$ Online Published: November 15, 2014

doi:10.5539/res.v6n4p42

URL: http://dx.doi.org/10.5539/res.v6n4p42

\begin{abstract}
The environmental crises of today are the resultant of human conduct with respect to conceptual, social, political and economical aspects. The conceptual-philosophical factor is the source of all these crises with an undeniable effect. Francis Bacon's philosophical basics with no doubt are the most influential, regarding bio-environmental phenomena. He deals with the progress of the world in a manner where almost all components that contribute his philosophy to anthropology and or biology and even logic must serve human welfare at nature's destruction cost. The attempt is made here to explain the domain of his philosophy in a manner where the effects of his opinions in initiating natural disasters are exposed. Our claim is that he is placed in the environmental ethics group of anthropocentrism.
\end{abstract}

Keywords: francis bacon, environmental crisis, human-nature correlation, Anthropocentrism

\section{Introduction}

Bioethics is concerned with human-nature correlation. The progress of either one of these subjectivities of either or both constituent elements without "explaining them in a narrow margin" is of no use. Here, it is believed that the analysis and explanation of these two elements will bear fruit when they are considered as two foreign issues subject to individual comments. The acceptance of these ideas has made the authors to present their strategies in a manner where these issues are associated while their factual, not abstract nature is being analyzed. In fact in the domain of bioethics conjunction of human is foreign to the external environment while the analysis of the human interaction in the experimental reality takes place (Potter, 1971, pp. 5-7). Accordingly, the cardinal questions of this major issue are presented as follows:

- Correlation between Human and Nature is the constituent of which domain?

- Does the correlation between these two with all their existing potentials have a narrow margin or merely a specific limited overlap which connects them together?

- Is this correlation unilateral and or bilateral?

- How is the stance of philosophical thoughts evaluated in bioethics?

- In a more specific sense which is the Francis Bacon's philosophical notions' contribution to this mutual correlation?

- With due respect to Bacon's specific explanation of "Human" and the "World" and his definitions presented in a variety of philosophical domains, what does he recommend regarding the two domains of existence: a unilateral correlation (subaltern relation) and or bilateral (reciprocal relation)

- Which are the constituent components of human-nature correlation in Bacon's empirical doctrine?

By answering the above set of questions, a more correct and rational answer could be presented to Bacon's final notion on "Bioethics". The major issue here is to identify Bacon's thinking pattern regarding "Bioethics". To do this, first, the following two types of relations in the domain of Bioethics must be discussed, which would pave the way for discussing other issues we face regarding his doctrine. 


\section{Human and Nature: Subaltern Relation and or Reciprocal}

Today's modern Bioethics science (Wenz, 2001, pp. 261-285) is endowed with four canonic Bioethics values: Anthropocentric, Zoo centrism Ethics, Life-Centered Ethics and Universal Consideration. The focus of all four is on one issue, the "Two types of relation" between human and nature. In a sense after analyzing the content of these four doctrines the subaltern and casual relations regarding Bioethics are obtained, the focal points where on one side there is human with all its behavioral and thinking actions and reactions and on the other, the nature with its organic, vegetative and animal order. In reality, a portion of existence is independent and of free will in its actions, while the other's actions are subject to will. The essence of the subaltern relation is in the nature of will and a higher level force in the physical world, named human. In reality with respect to subaltern relation, human is considered as the master and nature as the subject. In this relation human owns the right which is not obligated to nature; while, it is the nature that has to fulfill the master's needs, unilaterally.

By addressing a question on a critical point regarding the features of subaltern relation, the discussion will go on: Does the subaltern relation recognize and respect the relation between Human and Nature in a collective or composite form?

Any answer to this question will be valued high in Bioethics. In a general sense, it could be responded that: with no doubt, the followers of subaltern relation will consider Nature in its "collective" form, just like the human's relation with a "tree" that can in no way explain the same relation with the "mountain"; in fact, the separated nature, among the physical phenomena of what exists in nature constitute the prevailing soul and spirit of subaltern relation.

Regarding the casual relation, it is a view point emphasizing on the unified reality nature of the initial phenomenon of the world where every being is considered as an independent identity; accordingly, here, all beings are endowed with the uniform ethical generosity. Such a relation is not only prestigious for human but admirable towards the innate values of all beings in nature. The emphasis on preserving the nature's rights on human side is another code of conduct in this type of relation. Accepting the fact that the world resembles a family where the members are its constituents (all citizens of equal right) human cannot possess the right to supremacy and dominance in the essential component of this relation (Leopold, 2001, pp. 120-135).

Now, by assessing the nature of these two relations, where is Bacon's stance in this respect?

Is he a devotee of a subaltern or a casual relation?

The assessment and explanation of Bacon's philosophical structures and reviewing his notions in Anthropology and Biology can help us to have a precious conclusion on this matter. Of course his role as a revolutionary scientist should not be ignored. In fact the master key, in comprehending the philosophic structures of Bacon's scientific revolution is the two domains of changes in direction and objectivity of philosophy. With this approach we will record the following issues with respect to his doctrine:

\section{The Principle Doctrine of Anthropology}

- The ultimate objective of creation is human and the ultimate objective of human is the potential in materializing a "blissful life". (Bacon, 2000, pp. 80-85)

- The necessity of human being equipped with knowledge, science and technology is the fundamental principle of living this life on the earth; therefore, all these forces should be combined to expand the human territory in nature and fetch for human's blissful life. (Rossi, 1965, p. 49)

- To accomplish the ideal life there is no need for human to be equipped with the ethical virtues and features (Bacon, 2006, p. 157), since, according to this view the human blissfulness is worldly which can be obtained merely through science and empirical technology. (Church, 1974, p. 71)

\section{The Doctrine of Biology}

Secularization of the nature sphere (disconnecting the God-Nature contact) with the metaphysics domain through separating the "theology of nature" and the "theology of revelation" (Wallace, 1967, p. 72) has led to the elimination of final causes in the arc of descent of being and its cross reference to "natural absurdism" (Bacon, 2006, pp. 80-100), ending in disconnection of the physical and metaphysical ascending arc of being domain's connection (mere materialism in nature) (Bacon, 2000, p. 25; Anderson, 1975, p. 56). The idea here is that nature is nothing but lifeless matter, lacking any life and spirit.

By emphasizing on his own doctrine in the domain of anthropology Bacon practically introduces a being as the whole circle of existence in nature and the environment. He introduces human as the "Ultra man" and "Supreme will" of the nature. To him the natural world and its creatures either lack objectivity and or their objective is set 
as the introductory objective of the final objective, not its priority; therefore, to him reality merely is human and not his life in this world. According to Bacon, in the biologic domain, based on materialism, relieved from all ethical values available in nature, he refers to a kind of absurdism in the warp and woof (texture) of nature. By eliminating the ultimate causation in the nature has left human's hand free in determining the nature's fate in any form and manner.

In this respect in "New Organon" he writes "The reason for ultimate causation instead of causing scientific advances leads to its destruction". (Bacon, 2000, p. 121)

Here, it could be said that on one hand, in the domain of anthropology by setting human at the divine stage, rejecting God from all relations in the world and giving the bridle of all the affairs to human and on the other by diminishing the nature's status and discharging all features of nature from any divine value (including the ultimate causation and vitality) he leaves human hands free to loot and exploit the natural resources.

\section{Human's View on Nature}

One of the other major issues under discussion in human-nature relation agenda is the quality of human view on nature. This issue has so big a stance that the bigger portion of Environmental Bioethics is assigned to it.

The two canonic questions being addressed here are:

- What is human's notion when entering the celestial sphere of nature?

- After this notion is accomplished, which are the tools and the wisdom of human in relation to nature? Could they be the sense, mind or intuition?

In fact, Bacon, by answering the main question of this section, that is the manner of human view to nature, tries to establish his stance as being one of the four-fold theoricians in Environmental Bioethics. In addition to his explanation on the latter issue, he sometimes resorts to allegory, metaphor and simile formats in interpreting his own ideas. These interpretations reveal his true opinions in the domain of biology.

Expressions like "interrogating", "nature under pressure and persecution", feminine Nature" and "dominant human" are common in Bacon's literature. He was an expert in applying formal literary idioms in his works (Jahangiri, 1376, p. 10) but it would be a big mistake to consider the interpretations, allegories and metaphors in the philosophy of a man like him who's objective was nothing but changing the human's life style through dominance on nature as the literary arrays. We are of the opinion that application of such interpretations by Bacon is directed towards his own idealistic knowledge and the ultimate limit of elaborations regarding objectivity. Here, the attempt is made to express his view of the nature by applying the interpretations available in his own philosophy. The processing and explaining of these interpretations would give us the opportunity to use his name without any doubt and or fear with respect to all that are for or against environmental issues. One can ask the question like: Is Bacon concerned about the code of ethics in the environment and its ethical value? Or is he considered as the main provider of the basis of humanistic theory regarding environmental ethics with his array of unique ideas? To have a clear view on these questions pointing to one of the latest movements in the last few decades regarding the environment is of essence. This discussion has its important share in our study.

\section{Ecofeminism}

What is feminism and how does it relate to the environment?

How is Bacon's contribution assessed with respect to ecofeminism?

Feminism is a movement claiming that machoism has harassed feminism in the due course. In reality feminists seek freedom of their own in variety of aspects. The term ecofeminism entered the environmental domain in $80 \mathrm{~s}$ by Francoise D. Eaubonne. Karen J. Warren is among the ones who emphasized on the spread of this term in other domains. In fact, ecofeminism must be classed as a revolutionary act since its axiomatic terminologies consist of "dominance", "aggression ", "sex" (inter course and femininity) and "equality". It can be said that this concept has crossed the borders and has engulfed the environmental domain. Consequently, the terminologies above are the canons to be fired against any type of "aggression and dominance" in any domain, be it man to woman, human to nature, stratum orientation, racism etc. Despite the idea of activists any ethical order against the objectives of this ideology is considered as a defective and a cruel order: This view is against any type of duality value where man is said to be the superior and woman the inferior.

Now, where is the interface of femininity and nature?

Bacon has the most renowned expressions in most of the themes regarding feminism in a simile and metaphor form regarding nature and the female nature of the nature. At this conjunction the array and ideas of Bacon, in 
practice, are applied in the domain of bioethics, something considered as the best mental source that nurtures the environmentalists' brains who have realized his interpretations and metaphors in a good sense. To Bacon, the nature has adopted a concept regarding gender that is subject to subjection of man (Anderson, 1975, p. 25; Merchant, 1992, p. 740)

To him science resembles man and nature resembles woman. He draws a parallel between the man woman and science nature obligations. This scientific metaphorism of nature as a live mother who gives life to a non-living matter that grows subject to exploitation corresponds to the capitalistic order. C. Merchant, one of the renowned thinkers in bioethics, by referring to this phenomenon says "Killing a mother, running an autopsy and or cut the body in pieces is not an easy task" (Merchant, 1980, p. 182; Merchant, p. 193).

The seeds planted by Bacon for the purpose of blissful life for human in his experimental philosophy, not only did not bear fruit but in fact, grew to be a license for exploitation and stripping nature from God given possessions by the capitalistic and dominant order, through the post-modern human. To him nature is full of valuable secrets, necessary for human welfare which should be revealed and since nature tolerates force, revealing these secrets is inevitable (Bacon, 2000, p. 102). He resembled nature to a wild and untamed woman who must be tamed by man and become obedient. The superficial and inner mines, water, and all the natural resources are placed in the nature's material womb; hence the knowledge, science and technology must exert pressure on the nature to discharge these resources (Merchant, 2012, pp. 10-32).

This type of metaphor regarding the feminine nature of the nature on one hand and exposing it to torture on the other in order to reveal the secrets is unique to the main trend of Bacon's philosophy.

\section{Delinquency of Nature}

At the end of the Middle Ages, when Bacon's doctrine was first introduced, the tranquilizing nature with its heavenly features gradually gave way to a cruel, harsh and delinquent one, and the question is "what has nature done wrong, and which secrets are concealed and hidden by it in order to consider her as a delinquent?

Why did the nature loving human become the enemy of nature after the scholastic era?

What was the crime committed by nature and what is Bacon's role in this phenomenon?

Before dealing with this issue, the issue of dominance of human on nature, something directly related to the issue, should be touched upon. Here, the exaggerated human stance by Bacon should not be overlooked in reference to his replacement formula, that is, "Human representing God (-) minus God ignoring human".

In the middle ages, human was busy discovering his lost reality in the nature and the reality-seeking knowledge was considered as his tool in this endeavor. Bacon, by making a change in this innocent relation claimed that human and his scientific search should serve a potential and beneficial purpose. He was referring to the power and dominance on the nature. To him science was the power's equivalent. If the Human's exploitative orientation on nature can be explored and scrutinized the objective of the following direct sequential order will be obtained:

by applying achieves earns ends up

Perceiver human-----------> Nature --------> Explorations ------>Power --------->in Dominance

The initial move of inquisitive and potential power seeking human (instead of discovering the impossible truth) is from nature, which is an ascending pattern with a determined utmost limit ending up in generating strong and metamorphosed human.

How did Bacon design the strong machine that would generate the dominant human?

By considering Bacon's the "New Atlantis" and the role of Suleiman's House the issue would be somewhat clear. In this Utopia, Suleiman's House resembles the Thinking Room which is obligated to generate mechanical human. Bacon knew very well that nature has valuable treasures as resources, which when discovered would endow human with unutterable power. The inquisite and power seeking human must apply the knowledge about nature in order to dominate it. In fact, human's dominancy on nature is what the modern biologic sciences are all about.

Human worshiped, respected, honored and praised nature but now Bacon was thinking to destroy the nature and dominate it; in a sense, he wanted to interrogate nature in today's man's courthouse. To pronounce this issue he applies the metaphoric approach. By using terminologies like "interrogation" and "Nature subject to persecution", Bacon tries to induct the notion that nature is not a good mother, but a, wrongdoer criminal who conceals many secrets from human. This language reminds us of the persecution of beliefs in the middle ages. Nature has never ending masks and is full of secrets; therefore, it should be subject to interrogation at all times 
like a criminal with a heavy file. In a sense, he wanted to say that by revealing each one of the secrets a lock is unlocked and the modern human is empowered more.

These interpretations by Bacon, resembling nature to objects that arouse human greed in theory have a significant effect on the environmental crisis. The innumerous manipulations of the environment based on such doctrines in addition to the criticisms by the environmentalists all convict Bacon's exploitative mentality regarding nature. In order to generate powerful human, he freed himself from all obligations and crossed all red-lines with respect to nature as far as science is concerned.

\section{Religious Authority and Dominance of Human on Nature}

Bacon has resorted to the biblical doctrines to verify his conduct when he established the idea of human dominance on nature by running an autopsy on the body of nature and even justifying the interpretations that promote the modern human dominance, the causation of all environmental disasters. He claims that all he recommended with respect to "leading a blissful life due to accomplishing human dominance on nature" are divine.

Does Christian doctrine promote natural disasters? Or Did God issue the order of nature's destruction after it was created? Or to which section in Bible does Bacon refer to?

He believes that Christianity verifies the supremacy of human to other beings; thus, the only being entitled to ethical conducts and ethical values is the human. Regarding Adam and Eve's expulsion from the heavens he claims that human should be returned to the kingdom. He supports these ideas by noting that the canonic condition for such dominance is the correct perception of the laws of the nature by posturing interrogation of the nature as a prerequisite. By referring to the Pentateuch of creation from the old testament where Adam is told "With the sweat of your brow you will eat your food until you return to the ground, since from it you were taken" (Genesis 3/19) or "And God blessed them, and God said unto them, Be fruitful, and multiply and replenish the earth, and subdue it: and have "domination" over the fish of the sea, and over the fowl of the air, and over every living thing that moved upon the earth" (Ibid 1/28). Here it could be deduced that philosophy must advance through materialization of the blissful life of human that is the dominance on the nature. By referring to religious sources he supports his wrong interpretation of the pretext in interrogating the nature. It is obvious that attempts are made by Bacon in creating a heaven on earth (against the other worldly heaven) and giving sovereignty to modern human (against sovereignty of God).

\section{Commenting and Assessing Tools of Recognition}

The tools used in recognizing human in seeking the truth is of high essence. These tools are defined in relation to the nature of the truth and its utmost limit. The nature of the truth selected by Bacon is already discussed, now it is necessary to criticize and evaluate the tools he used in this respect in an independent manner.

How are the role and the stance of epistemic methodology of Bacon justified?

Did he use all the epistemic tools necessary in obtaining the truth?

How is the correlation among epistemic methodology, bioethics and natural and environmental disasters explained?

In order to make this issue more coherent it is worth referring to Bacon's philosophic objective, which is the head-light in revealing all related analysis towards his doctrine.

Converting the Earth to Heavens, where human will go on with living in comfort and welfare is his utmost goal which could be accomplished through science and technology, the two elements that would convert human in lead character in the celestial sphere of the nature. This type of targeting on materialization of life on this earth calls for a specific pattern and trend in philosophy and Bacon did this by separating the divine theology and the nature by concentrating on empirism.

Registering Bacon in the school of empirism is due to the analysis made on his philosophy in addition to his clear and formal propositions which leave no room for any doubt.

Many times he has criticized Plato and Aristotle regarding their indifference towards biologic and experimental sciences and merely focusing on theoretical sciences.

Bacon has accused them of being sophists (Bacon, 1966, B, p. 83 and 2000, pp. 62-74). In his famous statement regarding the priority of theoretical logic to empirical issues he says "In Aristotle's naturalia and metaphysics the noise of logic [logical deduction by analogy] is more than that of the nature" (Bacon, 1966, A, p. 112).

His criticism was not merely on the rationalists but on philosophers and thinkers who do not recognize any other 
approach towards achieving the truth except mere empirical approaches. He was not pleased with Plato and Aristotle, the symbols of rationalism, since they have valued the metaphysical and arc of descent while ignoring the empirical aspect of the issues. He did not try to find the truth in thinkers like Xenophon who did not recognize any celestial sphere but the physics domain (Bacon, 2006, p. 105).

To Bacon the generis of truth has properties to which the pure empiricists and rationalists have no access. He draws the path by saying "These (pure empiricists) suffice to limited empirical conducts and do not apply their rationale and keep collecting grain and consuming them, just like the ants." (Bacon, 1966, A, p. 131)

Bacon criticizes the philosophies which are without practical concepts and do not constitute the back bone of fulfilling this world's needs in life (Bacon, 2000, p. 72). In fact the essence of his philosophy is to give priority to the authenticity in action that is a philosophy where explanation, innovation and empirical observations are prior to the theoretical and useless issues. To him sense has superiority to rationale (Bacon, 2007, pp. 2-10). He regarded his philosophy as to be based on experiment "My philosophy is based on observation and experiment depicted from the textual content of the world not imaginative virtues and rationale." (Bacon, 2000, p. 100)

Bacon's methodology in the epistemology domain should be attributed to sense and experience than rationale. Although he does not reject rationale explicitly his philosophic approach and directive is arranged in accordance with empiricism. Accordingly, the question arises: Has Bacon proposed any method in achieving the metaphysics domain?

Did he consider the presentiment of methodology? It is obvious that the separation between physical and metaphysical domains is considered as the bases of his empirical philosophy. Dividing theology into divine and natural is Bacon's innovation through which he separated metaphysics from the celestial sphere of physics (Bacon, 2006, pp. 80-101).

To him the nature is based on natural philosophia and the Holy book is assigned to the Divine philosophia with no intermediate link between them since any connection between these two domains would lead to eclecticism; hence, the disintegration of metaphysics and philosophy.

He names the metaphysics the domain of belief which is found in the Holy book, exclusively in nature through profound thinking. Said otherwise, since issues like God, soul, essence and in general what constitutes metaphysics cannot be conceived by our sense, discussing them is of no use and instead of contemplating in this domain the human's welfare should be the concern. To him, "these philosophers (metaphysicists) concentrate on studying the initial principles (the essence) and generalities and as a result they would reach the potential matter due to the natural abstraction or reach the inseparable element. These issues, even, if correct, are worthless to human since they do not affect their welfare (Bacon, 2000, p. 70). Here, it becomes clear that Bacon does not respect the philosophers of metaphysics, since they are not involved in the faith of human and his lifestyle, which is more important than what those philosophers seek. Accordingly, if we say that Bacon's philosophy is of the positivism type, the source of which is rooted in sense and the theme is the phenomenon with no loyalty to any method but induction, it will not be considered as an exaggeration. He searches for explanations, innovation and techniques such as: aircrafts, ships, telescope and canons in the hearth of nature. In order to achieve these requirements, he had determined the grounds and limits beforehand. Eliminating the final causes from the nature, mere sense of regarding nature as material, eliminating God from nature, introducing human as the hero of existence "humanism" and deposing all ethical and value properties from him (introduction of modernized human instead of divine human) provided the grounds where human was trained and tamed like a robot to achieve the mundane issues.

In general, according to what was discussed on Bacon's doctrine it could be deduced that: "human" to Bacon is transformed to a human with no ethical value and properties and "nature" to him is completely material, with no vital signs, no final objectives; hence, empty of any kind of divinity.

\section{Logic and Bioethics}

What we usually know about logic is its Aristotelian definition: a total of rules observation of which keeps the mind away from thinking wrongly. But it seems that Bacon's scientific revolution and its final objective that is welfare and blissful life for human influenced the human philosophy and especially the logic. To him "all roads end to "human welfare". He did not forgo any attempt in pushing his theory until the domain of logic was converted into a "technique" for dominating the nature; a technique that influences nature and the environment as a tool used by human. Before entering this domain, for better cohesion of the issue the philosophy of human should be separated into "Anthropology" and "Political Philosophy" (Bacon, 2006, pp. 100-108).

Anthropology is a domain where the individual and the society are analyzed. Physiology and Divine knowledge 
are branches of anthropology (Ibid, pp. 106-110). Bacon divides the Divine knowledge into two sections: the knowledge of essence or the soul of nature and the knowledge of faculties and the deeds. Since, to him, the discussion on divine essence is reserved to the revealed theology (the Holy Book); therefore, he has kept it away from the domain of the philosophy.

According to Bacon, any discussion on soul is merely theological not noetic. But the faculties and deeds of soul, where the science of logic is a branch of, are of two sections: noetic faculties and ethic faculties. Said otherwise, logic and ethic are the offspring of soul faculties.

What is logic and how does it connect to bioethics?

Does logic enter the domain of nature directly or as a tool?

To Bacon, logic is the tool to reveal the truth and the manner of acknowledging it. Unlike other philosophers he does not pronounce the usual comparative nature of the truth, but discovering it, (to him truth is where the profit lies) the sole objective. He considers the studies on mental mistakes and errors (the idols) which distance the brain from the truth as a duty of logic. Bacon's logic is divided in four techniques:

1) Inquiry or innovation, 2) Education or Judgment, 3) Custody of memory and 4) Elocution of tradition

His reasoning on this division is attributed to his scientific revolution which founds his philosophy; as if "better life" of human needs a tool named logic. He believes that the coordinates of logic are responsible for innovation and modern equipments/tools production, judgment, maintenance and transportation (Ibid, pp. 120-135).

When he introduces the definition of logic as "discovering the truth" to him truth is nothing but the innovation of goods, things that were unknown to human brain (Ibid, pp. 122-127). It is observed here that there is a difference in the classic logic and what Bacon has in mind as the final objective.

Perhaps one of the main parts of Bacon's human philosophy with respect to his opinions regarding nature and natural disasters that could imply a discount on criticisms addressed on bioethics is the issue of moral philosophy. Since the issue of ethics is the main branch in human-philosophy, it would have been very appropriate and worthy if Bacon had considered some discussions regarding bioethics and environment in his philosophy.

We accept that bioethics is considered as a new and young science, but Bacon, knowingly puts the nature in human hands as a tool with the knowledge that such permission in concurring nature would have environmental problems, the dilemma that human is facing today.

In fact this objection is justified as: Despite his instrumentalist view on nature and his mere order in autopsy of nature why did not he introduce bioethical measures appropriate to his empirical philosophy to human?

Why did not he mention anything about bioethics which has the same faith as the techoethics in his philosophy where the final objective is the blissful life achieved through autopsy of nature?

If only his ethics regarding nature's support would have been in proportion with his empirical philosophy where his revolutionary notions are generated from he would have not made his instrumentalist view on nature as an imaginary one.

\section{Conclusion}

Francis Bacon, with his alternative thinking manner and suppositions on the anthropologic and biologic predicates has designed a mechanism pregnant with environmental disasters. We believe that the main reason of this outcome is unloading the real fundamental philosophical conceptions such as God human, and God nature and loading false and untruthful definitions on the same concepts. Consequently, all the circumstantial evidences indicate that the final outcome of Bacon's philosophy in the environment domain will be inserting his name amongst the "bioenvironmental anthropocentrism" group members.

\section{References}

Anderson, F. H. (1975). The Philosophy of Francis Bacon. Publisher: Octagon Books.

Bacon, F. (2006). Advancement of Learning. DODO press.

Bacon, F. (2000). New Organon. Cambridge University press. http://dx.doi.org/10.1017/CBO9781139164030

Bacon, F. (1908). Essays, Charles Scribner's Son. New York.

Bacon, F. (1966). The Masculine Birth of Time. Benjamin, Farrington, Chicago.

Bacon, F. (2009). New Atlantis. Scotts Valley.

Bacon, F. (1966). “A” The Refutation of Philosophies in Benjamin Farrington, the Philosophy of Francis Bacon. 
Chicago.

Bacon, F. (1966). “B” Thoughts and Conclusions in Benjamin. The Philosophy of Francis Bacon, Chicago.

Durant, W. (1951). The Story of Philosophy, The Lives and Opinions of the World's Greatest Philosophers. Time incorporate, New York.

Jahangiri, M. (1997). Lives and works and ideas of Francis Bacon. Scientific and Cultural Publishing Company.

Leopold, A. (2001). Eco centrism the land Ethic, Environmental Ethics, Reading in Theory and AOO Location.

Merchant, C. (1992). Radical Ecology. Psychology Press.

Merchant, C. (2012). Francis Bacon and the "vexations of art": Experimentation as intervention. The British journal for the history of science.

Merchant, C. (1981). Women and Nature, Is Nature Calling? Santa Rosa, CA: Pole bridge Press.

Merchant, C. (1980). The Death of Nature-Women, Ecology and the Scientific Revolution. San Francisco: Harper Collins.

Potter, V. R. (1971). Bioethics: Bridge to the further. Poinsettia: Englewood Cliffs n's.

Rossi, P. (1965). Francis Bacon from Magic to Science.

Wallace, K. R. (1967). Francis Bacon on the Nature of Man. Oxford University Press.

Wenz, P. S. (2001). Environmental Ethics. New York: Oxford University press

White, L. (1967). The historical Roots of our Ecological Crisis, Science, New Series. American Association Press.

\section{Copyrights}

Copyright for this article is retained by the author(s), with first publication rights granted to the journal.

This is an open-access article distributed under the terms and conditions of the Creative Commons Attribution license (http://creativecommons.org/licenses/by/3.0/). 